\title{
A CONFIGURAÇÃO DO LAZER NO ESPAÇO DAS UNIVERSIDADES DA TERCEIRA IDADE
}

\section{Minéia Carvalho Rodrigues ${ }^{1}$}

resumo

O grande desafio a que este trabalho se propôs foi o de desvendar o lazer no espaço institucional das Universidades da Terceira Idade. Para tal, buscamos verificar qual é o conceito de lazer que sustenta suas propostas, os conteúdos culturais de lazer predominantes, os objetivos de suas propostas em relação ao lazer, as atividades de lazer desenvolvidas e o que estão denominando lazer em suas propostas. Enquanto metodologia, o estudo foi realizado mediante a combinação de pesquisa bibliográfica com pesquisas documental e de campo. Na busca de compreender como se configura o lazer no espaço institucional das Universidades da Terceira ldade, procurou-se justapor os dados da pesquisa bibliográfica com os da pesquisa documental, da observação e da entrevista. Com a realização deste estudo, foi possível afirmar que o lazer é a essência das Universidades da Terceira Idade investigadas e configura-se, neste espaço institucional, por meio dos seus conteúdos sociais, físico-esportivos, manuais, intelectuais, artísticos e turísticos. Contudo, a negação

1 Graduada em Educação Física. Doutora em Educação Física. Professora Adjunta da Universidade Federal de Mato Grosso (UFMT), vinculada ao Instituto de Ciências Biológicas e da Saúde. E-mail: mineiacr76@gmail.com. 
em relação ao lazer, encontrada em ambas as instituições, mostra a necessidade de um maior aprofundamento em relação ao conhecimento sobre o lazer por todos os envolvidos nas Universidades da Terceira ldade, já que o lazer se constitui em um instrumento pedagógico para o desenvolvimento dos indivíduos. O estudo também revelou que as Universidades da Terceira Idade representam novos modos de vivenciar o lazer na velhice.

palavras-chave

Lazer. Envelhecimento. Universidades da Terceira Idade.

\section{Introdução}

Este artigo é resultado de um estudo sobre a configuração do lazer no espaço das Universidades da Terceira Idade (UNATI). Algumas ideias básicas constituíram o ponto de partida para a investigação: qual é a valorização dada ao lazer de acordo com as propostas das UNATI? Como se configura o lazer no espaço institucional das UNATI? Essas duas ideias básicas delinearam outras interrogações. Assim, as problemáticas deste estudo centralizam-se em torno de averiguar as UNATI:

- Qual é o conceito de lazer que sustenta suas propostas?

- Quais são os conteúdos culturais do lazer predominantes nas suas atividades de lazer?

- Quais são os objetivos das suas propostas em relação ao lazer?

- Quais atividades de lazer nelas são oferecidas e quais são as mais procuradas pelos idosos?

- O que estão denominando como lazer em suas propostas?

As respostas encontradas para esses questionamentos podem contribuir para área de estudos do envelhecimento, educação física e estudos do lazer, pois procuram conhecer e compreender as UNATI como uma possibilidade de desenvolvimento cultural, pessoal e social para os idosos, por meio dos conteúdos culturais do lazer. Este trabalho compreende uma combinação de pesquisa bibliográfica com as pesquisas documental e empírica (SEVERINO, 2000). A técnica de amostragem utilizada para a seleção das UNATI obedeceu a critérios não probabilísticos, intencionais, por acessibilidade e concordância. Na pesquisa documental, foi feito uso da análise de conteúdo dos programas das 
duas instituições que participaram da investigação. Para a pesquisa empírica, foi utilizada como instrumento de coleta de dados a observação assistemática e a entrevista semiestruturada.

\section{Referencial teórico}

O lazer direcionado a pessoas idosas emerge em um contexto no qual um conjunto de discursos amplamente divulgados pela mídia brasileira insiste na desestabilização de expectativas e imagens que se assemelham ao avanço da idade. Evidencia que a dimensão etária não é um marcador pertinente de comportamentos e estilos de vida e propaga uma série de receitas: técnicas de manutenção corporal, comidas saudáveis, ginásticas, medicamentos, bailes e outras formas de lazer que procuram mostrar como os que não se sentem velhos devem se comportar, apesar da idade.

Essas novas formas de comportamento são veiculadas pela mídia e criam um novo estereótipo, os "heróis do envelhecimento". Featherstone (1995) denomina heroes of aging as várias imagens veiculadas pelos meios de comunicação, mostrando pessoas que, em face do processo de envelhecimento, parecem permanecer eternamente jovens nos seus hábitos de trabalho, postura corporal, expressões faciais e comportamento geral. Na perspectiva de Debert (1999), essa ideia rejeita a própria velhice ao considerar que a idade não é um marcador pertinente da definição das experiências. Se anteriormente os idosos eram homogeneizados por uma visão de invalidez e perdas, hoje o são com base na imagem de um idoso ativo, saudável e em busca de atividades de lazer².

Esse lazer que traz um novo estilo de vida ativo se torna em um dos elementos fundamentais no processo de desconstrução da velhice e de construção da terceira idade. No primeiro processo, nega ou exclui os idosos dependentes, que não interagem socialmente, que não desenvolvem novos papéis sociais e que não buscam atividades de lazer; e, na construção da "terceira idade", coloca em evidência os idosos ativos, participativos, com um estilo de vida dinâmico, que buscam interagir socialmente, que se integram em novos papéis sociais e participam de atividades de lazer. Esse processo traz em si uma nova moral de envelhecer, que é a do idoso envolvido em atividades voluntárias, físicas, de lazer e de turismo.

2 Acredito que ambas as imagens afastam os idosos do lazer: a primeira, por desconsiderar as potencialidades da pessoa idosa; e a segunda, por negar a velhice, definindo condutas a serem assumidas e impondo novas formas de agir com as quais os idosos nem sempre se identificam. 
Essa noção de que o idoso deve se manter ativo está ligada à teoria da atividade que surge em oposição à teoria do desengajamento (SCHROOTS, 1996). A teoria da atividade enfoca que o envelhecimento bem-sucedido (successful aging) significa a manutenção, pelo maior tempo possível, das atividades iniciadas na meia-idade, e estas, quando necessário, seriam substituídas (HAVIGHURST, 1961). Essa teoria se assume, na sua globalidade, como um novo paradigma destinado a alterar a perspectiva e os estereótipos negativos associados aos mais velhos (FERNÁNDEZ-BALLESTEROS et al., 2011).

De acordo com a teoria da atividade, a pessoa que envelhece em boas condições é aquela que permanece ativa e consegue resistir ao desengajamento social. Para essa teoria, quanto maior o envolvimento dos idosos em atividades, maior é a satisfação e, consequentemente, melhores são a saúde física e mental, o autoconceito e a aceitação social. Para Torres (1999), o envelhecimento bem-sucedido é um valor norte-americano, socialmente e culturalmente determinado. Portanto, os conceitos resultantes de estudos que não consideraram as variações culturais devem ser questionados.

São várias as críticas à teoria da atividade, mas uma das principais é em relação à sua proposição básica - de que o "bom envelhecimento" é estar ativo, resistir ao desengajamento social, encontrar papéis sociais substitutivos, manter status e atividades -, que pode hoje ser considerada uma perspectiva "antienvelhecimento" (SIQUEIRA, 2002). De acordo com Doll et al. (2007), outra limitação dessa teoria é que, muitas vezes, ela é mal entendida quando aplicada na prática com os idoso, pois pode levar à falsa impressão de ativismo, isto é, na maioria das vezes, a teoria pode passar a ideia de que para se envelhecer bem é preciso que a pessoa esteja engajada constantemente em alguma atividade. Essa teoria desconsidera a heterogeneidade e a diversidade das experiências de envelhecimento e nega as suas características específicas, não aceitando nenhum outro modelo diferente do que o do idoso ativo.

Essa compreensão de que o idoso deve se manter ocupado com atividades de lazer carrega uma visão instrumental e funcionalista do uso do lazer, descaracterizando-o como direito social que todos os cidadãos - inclusive os idosos - têm em relação ao atendimento de suas necessidades. Assim, o idoso passa a ser visto como o foco de programas educacionais, de lazer e turismo, apenas na perspectiva de que é um grupo social a ser controlado e monitorado, principalmente no seu "tempo livre". A criação desses programas direcionados a idosos - Universidades da Terceira Idade (UNATI), Escolas Abertas à Terceira Idade, clubes e associações de idosos -, muitas vezes, estão 
mais voltados a demandas de contenção e enquadramento social do idoso do que à garantia de seu direito a espaços de sociabilidade, educação e lazer. $\mathrm{O}$ lazer, nessa perspectiva, passa a ser visto como possibilidade de manutenção do equilíbrio social, de difusão de novas formas de comportamentos sociais (inovadoras maneiras de viver e portar-se em sociedade, formas de vestir-se, alimentar-se, divertir-se, conviver, socializar, consumir, participar etc.), com objetivos claramente definidos de equilíbrio social, legitimando práticas e comportamentos a serem seguidos na construção de uma nova velhice.

\section{Materiais e métodos}

Ao longo da pesquisa realizada nas Universidades da Terceira Idade (UNATI) selecionadas (UNATI-1 e UNATI-2), no período de 2005 a 2006, foram utilizados diferentes métodos e técnicas, com o intuito de complementar, aprofundar e cruzar informações. A observação assistemática, a entrevista e as notas de campo foram utilizadas.

Em um primeiro momento, realizou-se aquilo que Magnani (1996, p. 16) chama de "participação de reconhecimento". Durante esse período, realizei observações assistemáticas, sendo que todas foram registradas no diário de campo. Concomitante às observações, realizei entrevistas semiestruturadas ${ }^{3}$ com os idosos selecionados, segundo critérios já apontados.

Com os dados das entrevistas e observações em mãos, iniciei a análise, procurando desvendar as mensagens explícitas e implícitas presentes nas entrevistas e anotações do diário de campo, pois, de acordo com Franco (2005), o ponto de partida da análise de conteúdo é a mensagem, seja ela verbal (oral ou escrita), gestual, silenciosa, figurativa, documental ou diretamente provocada. Necessariamente, ela expressa um significado, um sentido.

Por meio da análise de conteúdo, procurei desvendar mensagens implícitas e explícitas presentes nas observações (formas de comportamento, gestos, emoções) e nas verbalizações dos sujeitos entrevistados.

É pertinente ressaltar que, concordando com Triviños (1987), nossa análise não se restringiu só ao que está escrito no material, desvelando mensagens implícitas, dimensões contraditórias e temas sistematicamente silenciados.

Nesse processo de análise, emergiram quatro categorias, cuja análise apresento a seguir nos resultados e discussão.

3 As entrevistas foram gravadas em recurso digital e estão disponíveis para futuras averiguações. 
Após anos vivendo em um ritmo institucionalizado, em que a fragmentação do tempo supõe um corte no tempo do cotidiano, o idoso depara-se com um tempo desinstitucionalizado, que lhe causa certo estranhamento: o "tempo livre". Contudo, esse tempo não é totalmente livre, pois os idosos não conseguem livrar-se das amarras sociais do trabalho e buscam um novo tempo de lazer, institucionalizado com os mesmos horários e obrigações dentro da UNATI.

Na nossa sociedade, o trabalho é o lugar privilegiado das referências sociais. Ele estrutura o espaço, o tempo e as relações sociais. Enquanto categoria central na vida humana, afirma a existência individual e a identidade pessoal e social dos indivíduos.

Nessa perspectiva, o trabalho é categoria fundamental de sociabilidade humana, condição imprescindível na vida em sociedade. É atividade essencial da qual advêm todos os outros processos de interação, enquanto formas mais complexas da práxis social.

O trabalhador, acostumado a tantos anos de trabalho, de atividade intensa e diária, quando desobrigado desta, experimenta certo estranhamento por sua nova condição. Sente-se em um mundo desconhecido por si e não reconhecido socialmente: o mundo da aposentadoria. Agora, ele é dono do seu tempo, e o trabalho não se faz mais presente como definidor dos limites do "tempo livre". O aposentado vive uma angústia com essa apropriação do seu tempo, pois tem uma sensação de liberdade por não ter compromissos com horário, mas também vem o medo de sentir-se inútil para a sociedade. O idoso exprime, então, uma profunda relação de medo e de prazer com o "tempo livre".

Nas entrevistas realizadas, alguns sujeitos relataram que não tinham tempo para si e que, antes de frequentarem a instituição, todo o seu tempo era dedicado ao trabalho e às obrigações familiares. Abordam sobre uma liberdade, uma independência que veio com o desligamento do trabalho e com a diminuição das obrigações familiares. Para aquelas mulheres que não trabalham fora de casa, as obrigações familiares ocupam todo o tempo e têm um papel muito significativo.

Os idosos buscam dar utilidade para o seu "tempo livre", que lhes pesa nas costas, enfatizando que são pessoas ocupadas, reiterando a óptica do sistema capitalista, em que o tempo deve ser consumido, colocado em uso e justificado produtivamente. Na realidade, o que ocorre é que o "tempo livre" é automaticamente ocupado pelo lazer e por uma série de outras obrigações, numa relação, muitas vezes, mecânica e reducionista, já que elas vêm para compensar a perda do trabalho e a diminuição das redes sociais, cumprindo, 
assim, um caráter funcionalista ao favorecerem o ajustamento das pessoas ao sistema social vigente.

Essa óptica funcionalista está ligada a um modelo de envelhecimento ativo. Alves Junior (2004) esclarece que a vida associativa no Brasil marca o início da institucionalização de um modelo de envelhecimento que, a nosso ver, estende-se até os dias de hoje.

Esse novo modelo traz consigo uma retórica de como envelhecer bem, com medidas concretas para a manutenção da boa forma, tais como exercícios físicos, alimentação saudável e novas formas de vestir-se e de relacionar-se com o corpo, com a família e com os amigos. Muitas vezes, o que os idosos buscam na UNATI é um "bom envelhecimento", um modelo ativista. As UNATI devem estar atentas, buscando esclarecer os idosos a respeito dessa retórica do "bom" e do "mau" envelhecimento, não negando as novas características dessa fase da vida.

\section{Entre o conhecer e o lazer: UNATI, espaço de apropriação ou negação do lazer?}

Ao tentar entender qual é a compreensão que os entrevistados têm da UNATI e o que eles realmente buscam, pode-se notar que parte das pessoas nega aquele local enquanto espaço de lazer. É o caso da entrevistada Flor-de-lis (UNATI-2). Quando a indaguei se considerava a UNATI um espaço de lazer, ela foi incisiva na resposta: “Não, de lazer, não!” Questionei-a e ela apresentou a seguinte resposta: "Porque é uma instituição de ensino e, como tal, ela tem que ser respeitada" (Flor-de-lis). Pode-se inferir que o entendimento do lazer é o de que ele não é sério e que, portanto, não oferece respeito e credibilidade à instituição que quer se utilizar dele.

Outra entrevistada, Flor-de-abril (UNATI-1), apresentou a seguinte resposta: “Também eu vejo mais o lado cultural em primeiro lugar, mas também fornece uma grande probabilidade de lazer pelas oficinas que eles oferecem." Essa fala evidencia que a entrevistada dissocia lazer de cultura, entendendo que esta é mais importante que aquela. A idosa não tem ciência de que o lazer é uma das mais importantes formas de manifestação cultural e um espaço para participação em que as pessoas podem usufruir e criar cultura.

A noção que as pessoas têm de lazer é que são atividades meramente consumidas, sem qualquer comprometimento com o processo educativo. Nas falas, existe certa distância entre o conhecer e o lazer, como se fossem excludentes. Este último, na concepção dos idosos, parece ser vazio de qualquer 
conteúdo educativo ou conhecimento significativo para o desenvolvimento das pessoas. Os entrevistados parecem ter receio em admitir que vão até a UNATI em busca de lazer. Digo isso porque evidencio algumas contradições nas falas das entrevistadas já citadas. Como visto, todas desconsideraram a UNATI espaço de lazer, mas, quando as questionei se realizavam alguma atividade de lazer, com exceção da Flor-de-abril (UNATI-1), todas entraram em contradição, relatando as atividades de lazer que vivenciavam naquele espaço.

Alves Junior (1994) encontrou dados semelhantes em sua pesquisa realizada na França, numa universidade de "tempo livre". Ele relata que os idosos responsáveis pelas atividades desenvolvidas nas associações procuraram sempre distinguir as atividades por eles praticadas como sendo de ensino e pesquisa e não de lazer e ocupação do "tempo livre", como as que seriam realizadas em clubes, o que se poderia também identificar, respectivamente, como um "bom" e um "mau" lazer, com o primeiro merecendo um reconhecimento social semelhante ao que se dá ao trabalho, e o segundo desqualificando como um simples preenchimento do tempo.

Visualizamos, durante as observações, que apesar de não verbalizarem na entrevista a existência do lazer na UNATI, os idosos vivenciam o lazer nesse espaço com muita alegria, descontração e prazer. O lazer está presente em todas as oficinas, cursos e palestras desenvolvidas por ambas as instituições. Podemos, inclusive, afirmar que o motivo que leva os idosos a frequentarem a UNATI é o lazer, que se revela nos seus diversos conteúdos culturais, assunto que será discutido no item a seguir.

\section{Os conteúdos culturais do lazer}

Para analisar as atividades desenvolvidas pelos idosos na UNATI, utilizei as categorias de Dumazedier (1973). Tenho ciência de que a classificação proposta por ele possui limites, que já foram apontados por Faleiros (1980), mas que, para o propósito, é a mais adequada.

Com relação aos conteúdos culturais do lazer, Dumazedier distingue cinco áreas de interesse: (1) manuais, que está relacionada com a capacidade de manipulação, seja para transformar objetos ou materiais, seja para lidar com a natureza; (2) intelectuais, ligada à busca de novas informações reais, objetivas e racionais; (3) sociais, marcada pela busca de relacionamentos e contato com outras pessoas; (4) físico-esportivos, em que ocorre prevalência de movimento ou exercício físico; e (5) artísticos, caracterizado pelas diferentes manifestações artísticas, baseadas no imaginário, nas emoções e nos sentimentos. Camargo 
(1999) acrescenta a esses mais um, o turístico, caracterizado pela quebra da rotina, pela busca de novas paisagens e de novos conhecimentos. Por intermédio das observações, das entrevistas e da análise dos documentos, pode-se verificar que todos os conteúdos culturais de lazer estão presentes em ambas as instituições, alguns com maior predominância que outros, como se verá a seguir. A análise não ignora que, em uma atividade, são encontrados mais de um conteúdo cultural, contudo, quando se classificou as atividades desenvolvidas na UNATI dentro de determinado conteúdo, considerou-se a predominância deste em relação aos demais conteúdos.

Nos interesses intelectuais, é predominante a busca pelo conhecimento por informações objetivas ${ }^{4}$. Os conteúdos intelectuais podem manifestar-se em palestras, leituras, seminários, cursos, jogos. Na UNATI-1, esse interesse manifestou-se na leitura, nas palestras e nos seminários. Na UNATI-2, encontramos o predomínio das mesmas atividades, sendo que o curso de informática foi muito enfatizado pela maioria dos entrevistados.

Os interesses artísticos estão relacionados com as imagens, as emoções e os sentimentos. Podem manifestar-se por meio do interesse por música, televisão, cinema, teatro, museu e visitas a bibliotecas.

Os conteúdos artísticos aparecem nas falas de duas entrevistadas, sendo uma de cada instituição: "Eu gosto de cinema, teatro, shows, quando possível, e as viagens oferecidas pela UNATI, eu participo de todas" (Flor-de-abril UNATI-1). Vemos também na fala da Amarílis (UNATI-2) a preferência pelos conteúdos artísticos do lazer: "Cinema, teatro, eu gosto de ler, sempre estou fazendo alguma coisa."

Os interesses manuais estão relacionados com a capacidade de manipulação, quer para transformar objetos ou materiais - por exemplo, o artesanato e a bricolagem - quer para lidar com a natureza - por exemplo, a jardinagem e o cuidado com animais (MARCELLINO, 1983, p. 43).

Na UNATI-1, os interesses manuais não se manifestaram no semestre investigado, pois não foi oferecida nenhuma disciplina ou oficina que tratasse desse interesse. Na UNATI-2, os interesses manuais concorrem com os sociais e físico-esportivos. Sendo citada pela maioria, a oficina de arte aparece como a preferida.

Os interesses físico-esportivos estão relacionados com todas as atividades nas quais prevalece o movimento ou o exercício físico. Podem manifestar-se na

4 De acordo com Melo e Alves Junior (2003), o envolvimento com os interesses intelectuais não exclui a existência do uso do intelecto em outros interesses. Em todos os momentos da vida, a capacidade intelectual está em alerta, mas, nesse grupo de atividades, a ênfase central e a busca de prazer estão diretamente ligadas à atividade de raciocínio. 
prática de atividades físicas em geral. Na UNATI-1, esse interesse manifestou-se na oficina Redescobrindo o Corpo ${ }^{5}$; e, na UNATI-2, nas aulas de educação física e esportes adaptados.

Os interesses turísticos podem manifestar-se em passeios e viagens. Esse interesse manifesta-se com menor frequência em ambas as instituições. No semestre investigado, a UNATI-1 não contou com nenhum passeio turístico, e a UNATI-2, com quatro. Apesar de esses conteúdos aparecerem com menor frequência nos programas, a fala dos idosos mostra que estes indivíduos tiveram experiências organizadas por ambas as instituições, e estas foram muito significativas em suas vidas.

Os interesses sociais manifestam-se quando se procura o relacionamento e o contato com outras pessoas. Esse interesse está presente na promoção da sociabilidade: festas, igreja, encontros em bares, restaurantes, parques, programas noturnos, bailes, passeios e atividades turísticas em geral ou grupos e associações.

A pesquisa mostrou que, em ambas as instituições, os idosos encontram a possibilidade de vivenciar os seis conteúdos culturais de lazer, entretanto a escolha em vivenciar cada um somente é possível se houvesse conhecimento das várias alternativas que o lazer oferece, o que não é comum à maioria da população. As pessoas não tiveram a oportunidade de desenvolver sua ação no tempo "livre", abrangendo os seis grupos de interesse, ou seja, exercitando o corpo, a imaginação, a habilidade manual e o relacionamento social, quando, onde, com quem e da maneira que quisessem.

\section{pedaço: sociabilidade e lazer}

As pessoas não vão até a UNATI apenas para preencher seu tempo "livre". A busca por esse espaço vai além disso, ou de "ocupar a cabeça" ou ainda de procurar por uma obrigação. As observações indicam que esse ponto de referência representa uma oportunidade de contato, de interação social, de estabelecer proximidade e laços, de encontro. É aqui que a noção de pedaço, abordada por Magnani $(1998)^{6}$, se faz presente, principalmente no que diz respeito à rede de relações sociais travadas.

\footnotetext{
5 Nessa oficina, são desenvolvidas atividades de alongamento, expressão corporal e maior ênfase é dada à dança expressiva.

6 O livro Festa no pedaço, escrito por Magnani (1998), torna-se clássico no estudo do tema. Mais do que a festa, a obra abrange formas de entretenimento com que a população da periferia de São Paulo preenche o tempo e o espaço de lazer. O autor coloca em destaque, por meio da pesquisa etnográfica, um assunto relegado pelos estudiosos: o lazer.
} 
Em ambas as instituições, o idoso busca uma forma de sociabilidade. As observações revelam que esse espaço funciona como um ponto de referência, o qual os idosos mostram nas vestimentas, na linguagem, nos gestos, na expressão corporal, na postura: o pedaço a que pertencem. A UNATI constitui-se em uma espacialidade em que as pessoas se identificam por símbolos, representações e mediações. Venham de onde vier, o que buscam é um ponto de aglutinação para a construção e o fortalecimento de laços. Quando os idosos se ausentam de suas casas e dirigem-se a esse seu pedaço, não o fazem com o objetivo apenas de ocupar o tempo "livre", de buscar conhecimento e atualização, mas vão até lá para encontrar seus companheiros, seus iguais, o "colega", como se refere Gloriosa (UNATI-1) às "velhas sabidas" do pessoal do pedaço: “O mais importante para mim é isso, o encontro com as pessoas..." (Primavera - UNATI-2).

Quando não existe mais o sentimento de pertencimento a um lugar e ao grupo de trabalho, são outros espaços, como o da UNATI, que fazem existir esse sentimento e criam novos laços sociais e valores, estruturando a identidade da velhice (PEIXOTO, 1997, p. 187). Na sociedade em que vivemos, as relações são pautadas no individualismo, na impessoalidade, no formalismo, diminuindo, assim, as possibilidades de contatos sociais e de estabelecimento de novas amizades, que é justamente o que o idoso busca.

Nas observações, pude perceber que em ambas as instituições os idosos transformavam aquele espaço em um local de encontro. Não vão até lá só para as aulas, tanto que alguns grupos chegam antes do horário para conversar, encontrar-se com as amigas e outros lá permanecem após o seu término. As falas de alunos de ambas as instituições confirmam as observações: "Chego antes para o encontro das colegas, né?" (Gardênia - UNATI-1). "Eu chego antes para o bate-papo, temos uma contadora de anedotas e de causos..." (Flor-de-abril - UNATI-1). Na UNATI-1, alguns alunos chegam antes e dirigem-se à sala da coordenação. Para alguns, o bate-papo antes da aula com a secretária é fundamental. Observei também, na mesma instituição, vários alunos espalhados pelo corredor e senti falta de um local mais adequado onde pudessem reunir-se. Na UNATI-2, os bancos espalhados pela escola são propícios aos encontros, à troca de ideias e de receitas e ao bate-papo antes da aula.

Segundo Peixoto (1997, p. 86), “[...] no imaginário das pessoas de mais idade que frequentam programas para terceira idade, a UNATI simboliza um território suspenso entre o público e o privado, entre a rua e a casa ou, simplesmente, o salão de festas de antigamente". Portanto, podemos afirmar que a UNATI simboliza o "pedaço".

A UNATI parece ser um território da existência de um sentimento de pertencimento e de identidade comum entre os membros da UNATI, permitindo 
que novas redes de sociabilidade sejam tecidas. A maioria dos autores designa sociabilidade como uma forma de estabelecer relações sociais, de convívio na vida social e coletiva, de interação entre as pessoas, isto é, relações tecidas pelos indivíduos nas diversas situações sociais.

Embora o exercício de sociabilidade experimentada na UNATI não substitua outras práticas, como a vida familiar, as relações de vizinhança e as práticas religiosas, considera-se crescente a valorização dessa experiência na vida dos entrevistados. Ao falarem do significado deste espaço em suas vidas, a UNATI aparece como lugar de encontro, de estar junto, de compartilhar, de "festa no pedaço". Os idosos valorizam muito a relação face a face, a interação com o outro e a possibilidade de conversar. $\mathrm{O}$ diálogo com o outro foi a forma de "lazer" mais citada.

Os idosos que vão até o espaço da UNATI para verbalizar sentimentos, emoções, ideias, conhecimentos, cultura e lazer, talvez não percebam, como eu percebi em minhas observações, que seus corpos também falam e revelam. Muitas vezes, um idoso carente de "gente" busca o outro por meio de sorrisos, de gestos, do silêncio, do olhar, do suspiro profundo, de pequenos toques e grandes abraços.

Não podemos negar que a UNATI, enquanto espaço institucional, permite uma sociabilidade denominada, por Argiles et al. (2013), de secundária. De acordo com eles, as formas de sociabilidade ocorrem em organismos institucionais públicos ou privados, associações, ONG, igrejas e escolas. ${ }^{7}$. Essas formas abrem uma rede de relações limitadas no que diz respeito à faixa etária, gênero, nível cultural e social. Nesse espaço de convivência e interação, existem regras de comportamento pautadas em certa formalidade, regras de estarem juntos, de atitudes, de sentimentos e de gestos. Todavia, a sociabilidade tecida a partir da intervenção institucional permite outras redes não institucionais que, segundo Argiles et al. (2013), são formas de sociabilidade primária que ocorrem entre amigos, parentes, colegas de trabalho e vizinhos, sendo práticas espontâneas de sociabilidade. As entrevistas indicam que a rede de sociabilidade dentro da UNATI é estendida para fora do espaço institucional pelo lazer (baralho, cinema, shopping center, lanchonete etc.). Os encontros intermediados por atividades de lazer fora da UNATI permitem que a rede de sociabilidade se estenda.

Grupos menores formam-se em torno de preferências em relação a alguns conteúdos culturais de lazer. Sendo assim, o lazer é responsável pelas redes de

7 No Brasil, encontra-se uma forte presença dessas formas de sociabilidade em UNATI, clubes e associações de aposentados. 
sociabilidade tecidas fora do espaço institucional e reforça a ideia de grupo, aproximando as relações. Esses encontros fora do espaço institucional, mediados pelo lazer, podem abrir novas oportunidades de encontro e fazer redes de sociabilidade surgirem.

Vale assim considerar, como Macedo (1986, p. 189), que mesmo ressalvando que há também uma dimensão conservadora e reprodutora das práticas sociais do lazer, essas práticas lúdicas não significam apenas conformismo e alienação, mas - como outros momentos da vida - incluem-se entre "formas socialmente disponíveis de mapear o mundo e encontrar o lugar nele". Podemos dizer que a festa no "pedaço" ainda existe.

\section{Considerações finais}

O referencial teórico mostrou que a construção sociocultural da velhice - marcada por diversos aspectos sociais, culturais e econômicos - desenvolveu-se nas últimas décadas, quando os indivíduos com idades avançadas se tornaram cada vez mais visíveis e passaram a ocupar diferentes espaços na organização social. A velhice saiu de uma situação de "invisível" para "identificada", gerando outra imagem sobre si, a qual contribuiu com a criação do termo "terceira idade". Verificou-se, também, como o lazer emerge nesse contexto, sendo um dos elementos fundamentais no processo de desconstrução da velhice e construção da noção de terceira idade, trazendo um conjunto de novos comportamentos e estilos de vida, que se identificam muito mais com os jovens do que com os próprios idosos.

O estudo realizado permite afirmar que as experiências desenvolvidas pela UNATI-1 e pela UNATI-2, no que se refere à educação de idosos, têm-se mostrado uma oportunidade dinâmica, flexível e acessível para atender aos desejos e às necessidades dos que os têm buscado. Esses indivíduos têm contribuído positivamente para o bem-estar, para a autoimagem e para as relações interpessoais. Parece haver um fortalecimento do grupo, que está relacionado a uma nova consciência social sobre o envelhecimento. Dessa forma, os idosos tornam-se agentes de modificação social, colaborando para uma transformação da imagem do velho na sociedade. A intenção não é negar as contribuições que as UNATI vêm implementando na educação de idosos, afinal sabe-se que elas vêm trazendo contribuições para que a velhice saia do "invisível". Contudo, esta pesquisa identificou alguns pontos que merecem reflexões, tais como: o significado do lazer encontrado nesse espaço, a necessidade de um maior conhecimento em relação aos seus conteúdos culturais, a necessidade de refletir 
sobre o atendimento à classe mais privilegiada de idosos, a necessidade de refletir sobre uma educação intergeracional, a negação da UNATI como espaço de lazer e a urgência de considerá-la um espaço autêntico de lazer.

No que se refere ao significado do lazer, foi identificado que a mesma falta de consenso encontrada no campo teórico está presente nos relatos coletados. O lazer assume uma pluralidade de significados na vida dos sujeitos, sendo que a maioria não possui uma resposta sistematizada acerca do tema. Visualizou-se, também, que o lazer, na maioria das falas, esteve associado aos conteúdos culturais, sendo identificada uma limitação conceitual.

Tais conteúdos necessitam ser reconhecidos profundamente por aqueles envolvidos nas atividades com idosos. Deve-se ter cuidado para que não haja um desequilíbrio entre os diversos conteúdos dentro das instituições, de forma que alguns não sejam valorizados em detrimento a outros. Percebe-se que as instituições valorizam os intelectuais, mas os idosos mostram preferência pelos manuais e físico-esportivos. Visualiza-se a necessidade de uma harmonia entre os diversos conteúdos culturais de lazer.

As observações revelaram que a UNATI é um espaço social de lazer em função de as atividades, de uma maneira geral, serem realizadas coletivamente, possibilitando o contato direto entre indivíduos. Representa, assim, uma possibilidade de as pessoas divertirem-se, descansarem e desenvolverem-se pessoal e socialmente, fruindo os seus valores. É o lazer que fez e faz com que essas instituições congreguem, a cada dia, um número maior de um público fiel. A UNATI pode ser ainda um lugar de organização da cultura, onde se desenvolva uma formação voltada para a promoção do homem, da sua conscientização e emancipação, para o seu acesso aos bens culturais e para produção e (re) elaboração da cultura, ou seja, para o questionamento e a modificação das condições objetivas e subjetivas que estão postas.

O lazer pode ser considerado uma semente que, se plantada em solo fértil e adequadamente adubada e regada, irá resultar em uma planta cujos frutos serão a possibilidade de uma geração com valores diferenciados daqueles encontrados na sociedade atual. O resultado do processo educativo, no âmbito do lazer, transcende em muito o próprio lazer. Aquele exerce influência em todas as dimensões da vida. Nesse sentido, a escola tem um papel fundamental de levar o seu conhecimento até as pessoas e proporcionar vivências de lazer em termos de qualidade e equilíbrio na vivência dos conteúdos culturais de lazer. 
Creio que foi possível, nos limites desta pesquisa, levantar aspectos interessantes referentes à apropriação da UNATI como espaço de lazer. Todavia, acredito que outras coletas sobre experiências regionais e nacionais de educação e lazer para idosos facilitarão a identificação de experiências similares, a difusão de novas ideias e a construção de modelos brasileiros de educação para esse setor, trazendo, assim, contribuições à pesquisa educacional e à sistematização de programas de lazer para idosos.

\section{THE SETUP OF LEISURE IN THE SPACE OF UNIVERSITIES FOR THE OLD AGE}

\section{abstract}

The big challenge this paper was confronted to was to discover leisure in the institutional space of Universities for the Old Age. For such, we researched about which concept of leisure sustains purposes of leisure, predominant cultural contents of leisure, objectives of the purposes related to leisure, activities about leisure developed and what is being called "leisure" in these purposes. As methodology, this study was conducted through the combination of bibliography research with documentary and empiric investigations. In the search of understanding how leisure is settled in institutional spaces of Universities for the Old Age, we tried to juxtapose data from the bibliography research with the ones from the documentary, observational and interview surveys. As results, we may claim leisure is the essence of the universities presented and it is configurated, in this institutional space, by means of its social, physical, manual, intelectual, artistic and turistic contents. However, the denial in relation to leisure, found in both institutions, shows the need of a larger relation to knowledge on leisure for all the individuals involved in this topic in Universities of the Old Age, for leisure consists of a pedagogic instrument for the individuals' development. The study also revealed that Universities of the Old Age represent new forms of living leisure in the old age.

keywords

Leisure. Aging. Universities of the Old Age. 
ALVES JUNIOR, Edmundo de Drummond. L'Université du Temps libre du pays de Rennes: un révélateur d'un modele social du vieillissement. Mémoire du DEA, d' Histoire, Civilization et Societés. Rennes: Université de Haute Bretagne, 1994.

Procurando superar a modelização de um modo de envelhecer. Movimento, Porto Alegre, v. 10, n. 2, p.57-71, maio/ago. 2004.

ARGILES, Carmen Terezinha Leal et al. Redes de sociabilidade: construções a partir do serviço residencial terapêutico. Ciência \& Saúde Coletiva, Rio de Janeiro, v. 18, n. 7. p. 2049-2058, jul. 2013.

CAMARGO, Luiz Octávio de Lima. O que é lazer. 3. ed. São Paulo: Brasiliense, 1999.

DEBERT, Guita Grin. A construção e a reconstrução da velhice: família, classe social e etnicidade. In: NERI, Anita Liberalesso; DEBERT, Guita Grin (Org.). Velhice e sociedade. Campinas: Papirus, 1999. p. 41-68.

DOLL, Johannes et al. Atividade, Desengajamento, Modernização: teorias sociológicas clássicas sobre o envelhecimento. Estudos Interdisciplinares sobre o Envelhecimento,Porto Alegre, v. 12, p. 7-33, 2007

DUMAZEDIER, Joffre. Lazer e cultura popular. São Paulo: Perspectiva, 1973.

FALEIROS, Maria Isabel Leme. Repensando o lazer. Perspectivas, São Paulo, v. 3, p. 51-65, 1980 .

FEATHERSTONE, Mike. Post bodies, aging and virtual seality. In: FEATHERSTONE, Mike; WERNICK, Andrew (Ed.). Images of Aging: Cultural Representations of Later Life. London: Routledge, 1995. p. 227-244.

FERNÁNDEZ-BALLESTEROS, Rocío et al. Productivity in old age. Research on Aging, Beverly Hills, CA, v. 33, n. 2, p. 205-226, Mar. 2011

FRANCO, Maria Laura P. B. Análise de conteúdo. 2. ed. Brasília: Liber Livro, 2005.

HAVIGHURST, Robert J. Successful aging. The Gerontologist, St. Louis, v. 1, n. 1, p. 8-13, Mar. 1961.

MACEDO, Carmem Cinira. Tempo de gênesis: o povo das comunidades eclesiais de base. São Paulo: Brasiliense, 1986.

MAGNANI, José Guilherme Cantor. Quando o campo é a cidade: fazendo antropologia na Metrópole. In: MAGNANI, José Guilherme Cantor; TORRES, Lilian de Lucca (Org.). Na metrópole: textos de antropologia urbana. São Paulo: EDUSP/FAPESP, 1996. p. 12-53.

Festa no pedaço: cultura popular e lazer na cidade. 2. ed. São Paulo: Hucitec/ UNESP, 1998.

MARCELLINO, Nelson Carvalho. Lazer e humanização. 3. ed. Campinas: Papirus, 1983.

MELO, Victor Andrade de; ALVES JUNIOR, Edmundo de Drummond. Introdução ao lazer. Barueri: Manole, 2003.

PEIXOTO, Clarisse E. De volta às aulas ou de como ser estudante aos 60 anos. In: VERAS, Renato Peixoto (Org.). Terceira idade: desafios para o terceiro milênio. Rio de Janeiro: Relume Dumará/UNATI/UERJ, 1997. p. 41-74.

SCHROOTS, Johannes J. F. Theoretical Developments in the Psychology of Aging. The Gerontologist, St. Louis, v. 36, n. 6, p. 742-748, Dec. 1996.

SEVERINO, Antônio Joaquim. Metodologia do trabalho científico. 21. ed. São Paulo: Cortez, 2000 
SIQUEIRA, Maria Eliane Catunda de. Teorias sociológicas do envelhecimento. In: NERI, Anita Liberalesso (Org.) Desenvolvimento e envelhecimento: perspectivas biológicas, psicológicas e sociológicas. Campinas: Papirus, 2001. p. 73-112.

TORRES, Sandra. A culturally-relevant theoretical framework for the study of successful ageing. Ageing and Society, Cambridge, v. 19, n. 1, p. 33-51, Jan. 1999.

TRIVIÑOS, Augusto Nibaldo Silva. Introdução à pesquisa em ciências sociais: a pesquisa qualitativa em educação. São Paulo: Atlas, 1987.

Recebido: 23/07/2014

Aceite Final: 24/08/2015 